\author{
Menara Lube Guizardi
}

Centro de Investigaciones del Hombre en el Desierto, Arica - Chile

\title{
Estereotipos, identidades, y nichos económicos de las migrantes brasileñas en Madrid
}

\begin{abstract}
Resumen: Las mujeres componen el 65\% de la inmigración brasileña en España. Esta feminización del flujo migratorio se vincula a la transformación de las relaciones de género vividas por estas mujeres en Brasil y en la sociedad de acogida. En Madrid, observamos una gran cantidad de negocios regentados por brasileñas - pequeños emprendimientos del campo de la hostelería o de estética y belleza. Sin embargo, ellas son más comúnmente empleadas en sectores no calificados con baja remuneración - en general relacionados a los servicios domésticos y al cuidado de niños y ancianos y la prostitución -, siendo en muchos casos asociadas a un estereotipo de hipersexualidad que influencia los nichos económicos a los que pueden o no acceder. El presente artículo analiza el rol económico que estas mujeres ocupan, y el conjunto de estereotipos raciales/nacionales con los cuales dialogan para lograr construir su inserción económica en España.
\end{abstract}

Palabras clave: inmigración; mujeres brasileñas; género; estereotipos sexuales; nichos económicos.

Copyright (c) 2013 by Revista Estudos Feministas.

\section{Introducción}

Las mujeres componen aproximadamente el $65 \%$ de la inmigración brasileña en España. Como veremos en el presente artículo, esta feminización del flujo migratorio es influenciada por un complejo de relaciones de género que se refieren no solamente a la inserción social de estas migrantes en su país de origen, Brasil, sino también a las relaciones de género vividas por las migrantes latinoamericanas en general en España. En el caso específico de las brasileñas - también ellas consideradas "latinas" - estas relaciones de género son además impactadas por un fuerte estereotipo internacional que les asocia a la sexualidad, y que fue construido, entre otras cosas, por las políticas brasileñas de atracción del turismo internacional de la segunda mitad del siglo XX. La sexualización de las brasileñas 
1 Beatriz PADILLA, 2008, también encontró una fuerte participación de mujeres brasileñas regentando pequeños emprendimientos económicos autónomos en Portugal. Esta coincidencia nos hace considerar que la iniciativa femenina en este sector tiene una dimensión estructural que se relaciona a una división de género del trabajo entre mujeres y hombres en origen. Debatiremos este tema en el ítem 3 del presente artículo. ${ }^{2}$ Adriana PISCITELLI, 2007, 2008a, 2008b. afecta directamente la manera como ellas se insertan económica y socialmente en la sociedad española, teniendo en muchos casos consecuencias bastante negativas en la vida cotidiana de estas migrantes.

En Madrid, observamos tres principales nichos económicos ocupados por las mujeres brasileñas. El primer de ellos es la creación y administración de pequeños emprendimientos del campo de la hostelería (bares, casas nocturnas, panaderías) o de estética y belleza (peluquerías, tiendas de ropa). ' Un segundo perfil de inmigrantes brasileñas se refiere a las mujeres que trabajan en sectores no-calificados con baja remuneración, en general relacionados a los servicios domésticos y al cuidado de niños y ancianos. En tercer lugar, ellas también aparecen vinculadas a la prostitución, un nicho laboral fuertemente relacionado a las brasileñas también en otras regiones de España y Europa. ${ }^{2}$

El objetivo del presente artículo es analizar los nichos de inserción económica de las mujeres brasileñas en la capital de España, observando no solamente el rol social que ellas ocupan, sino también el conjunto de imaginarios con los cuales estas migrantes dialogan para lograr construir su presencia en la sociedad española. En este sentido, analizaremos cómo la construcción de un imaginario eróticoexótico-sexual acerca de las brasileñas impacta el proceso económico de feminización del flujo migratorio. Explicaremos cómo un conjunto de estereotipos sobre la corporalidad de estas mujeres - que engendra mecanismos de vinculación de esta corporalidad a condiciones supuestamente raciales, puesto que la sociedad receptora tiende a asumir a las brasileñas como "de raza negra" (sic) y a vincular su corporalidad a esta imaginada condición racial - articula los espacios económicos a los cuales ellas pueden acceder, a la vez que impone fronteras sociales difíciles de ser traspasadas. Es importante subrayar que este encasillamiento económico se debe a (y se confunde con) el encasillamiento laboral, en la medida en que la inserción de estas mujeres en cierto estrato socio-económico viene fuertemente determinado por el nicho laboral a que ellas logran acceder, y que en última instancia está impactado por los condicionantes simbólicos-relacionales que el estereotipo sobre sus cuerpos hace pesar sobre ellas. Estos fenómenos se materializan a partir de una relación jerarquizada con la sociedad receptora, en la que las brasileñas son observadas, descriptas, e interpretadas a partir de una relación desigual con los y las "autóctonos" - lo que contribuye a que a estas mujeres se les atribuya determinados locus sociales considerados socialmente marginales.

Desde un punto de vista metodológico, la información que analizaremos se obtuvo a partir de estrategias 
${ }^{3}$ Agradecemos a Paula Villlanueva Casto, alumna de la licenciatura de Antropología Social de la Universidad Autónoma de Madrid quien, en el marco del desarrollo de su proyecto final de investigación, nos acompañó en gran parte del trabajo de campo que dió origen al presente texto. ${ }^{4}$ La ABHAl surgió aproximadamente hace cuatro años, siendo presidida por una inmigrante brasileña Fue creada con el propósito de servir como dispositivo de acogida a todo tipo de inmigrantes, con especial atención a los de procedencia brasileña. La entidad, sin embargo, no posee sede propia en Madrid, razón por la que hace uso del espacio alquilado por una Asociación regentada por el colectivo de inmigrantes dominicanos.

\footnotetext{
${ }^{5}$ Así, la información recogida seguía un orden quasi cronológico, estructurándose a través de la historia de vida y reflejando la trayectoria migratoria de la muje entrevistada desde su nacimiento en Brasil hasta el momento actual.
}

cualitativas y cuantitativas de investigación. ${ }^{3}$ Las estrategias cualitativas se desarrollaron a partir de dos mecanismos. Por un lado, contamos con las informaciones recogidas en nuestra observación participante etnográfica junto a la Asociación Hispano Brasileña de Ayuda al Inmigrante (AHBAI), ${ }^{4}$ realizada entre enero y agosto de 2010 . En estos ocho meses, realizamos visitas periódicas a sus miembros, lo que nos permitió una progresiva inmersión al colectivo y a sus redes sociales. De este modo, la asociación nos sirvió como principal plataforma de acción, facilitándonos el contacto con otros espacios, movimientos y personas. Las visitas al campo coincidieron tanto con las reuniones que el equipo directivo de la asociación realizaba de forma periódica (con una frecuencia semanal), como con otro tipo de actividades organizadas por el colectivo, tales como talleres temáticos-informativos de temas jurídicos y de asistencia psicológica, ferias de ventas de productos y comidas brasileñas, partidos de fútbol y las fiestas nacionales brasileñas. También acudimos a otras reuniones sociales, como las fiestas de cumpleaños de los miembros del colectivo y la exhibición de partidos de la selección brasileña en la Copa del Mundo de 2010.

A partir de los contactos obtenidos en nuestra observación participante, seleccionamos cinco mujeres brasileñas de diferentes edades a las que entrevistamos en profundidad, recopilando un material cualitativo de otra naturaleza. Estas entrevistas tienen una duración media de dos horas y los temas tratados en ellas respondían a tres ejes prioritarios, elegidos como forma de reconstruir una narración migratoria que interconectara la experiencia social en Brasil, la situación actual en España y las expectativas de futuro de estas mujeres. ${ }^{5}$

Nuestra investigación cuantitativa, a su vez, también se realizó a partir de una revisión de los datos estadísticos oficiales acerca de los migrantes brasileños publicados por el Ministerio de Trabajo e Inmigración de España (MTIN) y por el Instituto Nacional de Estadística (INE) de este país. Esta revisión nos permitió elaborar un panorama general de la inmigración brasileña en España, facilitándonos además aspectos centrales para comprender el papel de las mujeres en este colectivo migratorio.

El proceso de análisis de esta información cualitativa y cuantitativa se dio a partir de una comparación sistemática entre los datos obtenidos, y aquellos publicados por otras autoras acerca de las mujeres brasileñas en diferentes países de Europa. En este sentido, realizamos una detallada revisión de los trabajos publicados sobre el tema, enfatizando especialmente los estudios de caso en Portugal, sobre los cuales encontramos una amplia literatura. 
- Alexandra Gomes ALMEIDA y Ellem Saraiva REIS, 2007; Igor José de MACHADO, 2004a, 2004b 2005a; Kátia TÉCHIO, 2006.

${ }^{7}$ PISCITELLI, 2008a.

${ }^{8}$ Valéria Nely Cézar de CARVALHO, 2007; Mônica PEREIRA, 2008.

9 Judith MACDONELL y Cilene de LOURENCCO, 2009; Carlos ZUBARAN, 2008.

${ }_{10}$ Flávio CARVALHO y Flávio SOUZA, 2008; Amanda Regina GONÇALVES, 2007; PISICITELLI, 2007: TÉCHIO, 2006. La condición de indocumentación en los sitios de destino es una característica estructural de las migraciones internacionales emprendidas por ciudadanos de la América Latina y Caribe, siendo la regla más que la excepción entre migrantes desplazados del sur al norte del globo (Miguel VILLA y Jorge MARTÍNEZ PIZARRO, 2001).

"Esta misma información nos fue facilitada en una investigación anterior por los inmigrantes brasileños que regentan las asociaciones de capoeira en Madrid (Menara Lube GUIZARDI, 2011).

${ }^{12}$ Los datos sobre el empadronamiento son facilitados por el Instituto Nacional de Estadísticas (INE) a partir de su página en Internet (INE, 201 1). Las informaciones sobre las Tarjetas de Residencia, a su vez, fueron recopilados a partir de los Anuarios Estadísticos de Extranjería (1996-2003) y de los Anuarios Estadísticos de Inmigración (2004-2010), ambos publicados por la Secretaria de Estado de Inmigración y Emigración, órgano perteneciente al Ministerio de Trabajo e Inmigración de España. Todos los gráficos presentados son de produción propia y confeccionados a partir de estas dos fuentes estadísticas, cuyas referencias se encuentran recopiladas en la bibliografía del presente artículo.
En el ítem 2 del presente artículo, sintetizaremos las informaciones cuantitativas obtenidas en la investigación. En esta sección presentamos una revisión estadística sobre la migración brasileña en España, y realizamos un análisis sobre la inserción económica de las mujeres de este colectivo en Madrid. En el ítem 3, abordaremos de la construcción de un imaginario sexual y exótico acerca de estas mujeres y el papel que este conjunto de imágenes juega en la construcción de barreras sociales y raciales que a la vez provocan un tipo específico de inserción económica, impidiendo que estas mujeres mejoren sus condiciones de vida en la sociedad de destino.

\section{Migración brasileña en España $e$ inserción económica de las brasileñas en Madrid}

A semejanza de lo que ocurre con los brasileños en Portugal, ${ }^{6}$ Italia, ${ }^{7}$ Bélgica ${ }^{8}$ y Estados Unidos, ${ }^{9}$ verificamos un importante número de migrantes de esta nacionalidad en condición de ilegalidad documental en España. ${ }^{10}$ Según los relatos de las mujeres brasileñas que entrevistamos en Madrid, la regularización documental - por vía de regla vinculada a la obtención de un contrato laboral estable suele ser obtenida tras por lo menos cinco años de permanencia ilegal. ${ }^{11}$ Consecuentemente, nos enfrentamos con el hecho de que una parte expresiva del colectivo brasileño no está registrada frente al estado español, no figurando en las estadísticas de cuantificación de extranjeros. Esa realidad supone una dificultad empírica relacionada a la imposibilidad de cuantificar con exactitud las dimensiones de este grupo migratorio y de dar contornos a la presencia y participación femenina en el colectivo.

Las dos principales fuentes estadísticas de cuantificación de los extranjeros de que se dispone en España corresponden a los datos sobre el número de Empadronados en Municipios españoles, y a los datos sobre extranjeros con Tarjeta de Residencia en el país. ${ }^{12} \mathrm{Se}$ especula que ninguno de ellos refleje fielmente la realidad demográfica de la migración, puesto que el registro en ambos implica la superación de unos criterios alcanzados con dificultad por los migrantes, sobre todo en los primeros años tras su llegada a España. Entre los dos, sin embargo, el que se refiere al empadronamiento suele ser más fiable porque el registro municipal se obtiene con algo más de facilidad. Este registro que vincula el migrante a un determinado barrio o distrito urbano requiere solamente la confirmación de vivienda, un dato que se pode conseguir a partir de otro migrante ya asentado y empadronado en la 
${ }^{13}$ Según Joaquín ARANGO, 2003, p. 18, "Las redes migratorias pueden definirse como conjuntos de relaciones interpersonales que vinculan a los inmigrantes, a emigrantes retornados o a candidatos a la emigración con parientes, amigos - compatriotas, ya sea en el país de origen o en el de destino. La redes transmiten información proporcionan ayuda económica o alojamiento y prestan apoyo a los migrantes de distintas formas. De estas múltiples formas facilitan la migración al reducir sus costos y la incertidumbre que frecuentemente la acompaña (MASSEY et al., 1998 , p. 42-43). Las redes también pueden inducir a la emigración a través del efecto demostración". 14 GONÇALVES, 2007; PADILLA, 2005. ciudad (normalmente un familiar, amigo o conocido emigrado con anterioridad) y que "presta" su dirección para el registro del migrante recién llegado. Estas relaciones de ayuda mutua, por otro lado, se deben a la existencia de redes migratorias: ${ }^{13}$ vínculos de solidaridad y reciprocidad entre migrantes brasileños que se van distendiendo sobre el territorio español, interconectando personas y localidades en el país de origen (Brasil), a personas y localidades del país de destino (España). Estas redes migratorias tienen un fuerte impacto en la permanencia y sobrevivencia de los inmigrantes brasileños en el sur de Europa. ${ }^{14}$

La obtención de una Tarjeta de Residencia, por otro lado, está vinculada a la obtención de un contrato estable de trabajo - condición prácticamente ajena a buena parte de las brasileñas entrevistadas en Madrid, empleadas normalmente de manera informal - o al matrimonio con algún ciudadano de la Unión Europea.

Los dos gráficos que siguen ilustran respectivamente el número de mujeres y hombres brasileños Empadronados (1998-2010) y con Tarjeta de Residencia (1999-2010) en España. En ellos podemos notar la diferencia entre el total de hombres y mujeres registrados localmente en diferentes municipios españoles, y el número de aquellos que han podido legalizarse documentalmente. En 2010, los brasileños empadronados sumaban 146.941 personas, mientras los que disponían de una Tarjeta de Residente correspondían tan solamente a 57.459 personas $(39 \%$ del número de empadronados).

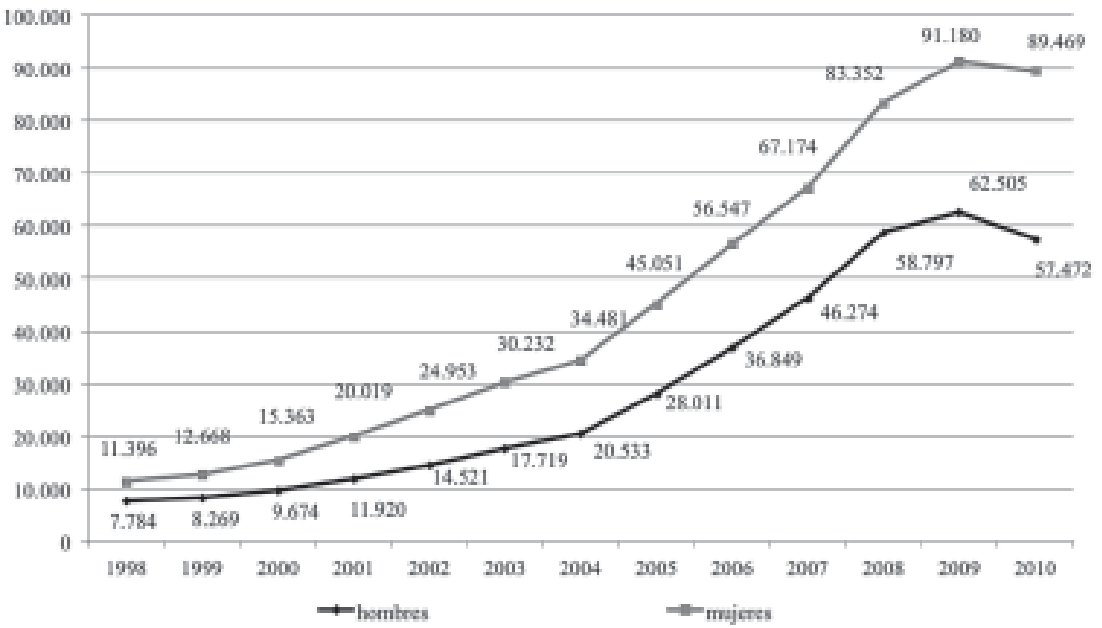




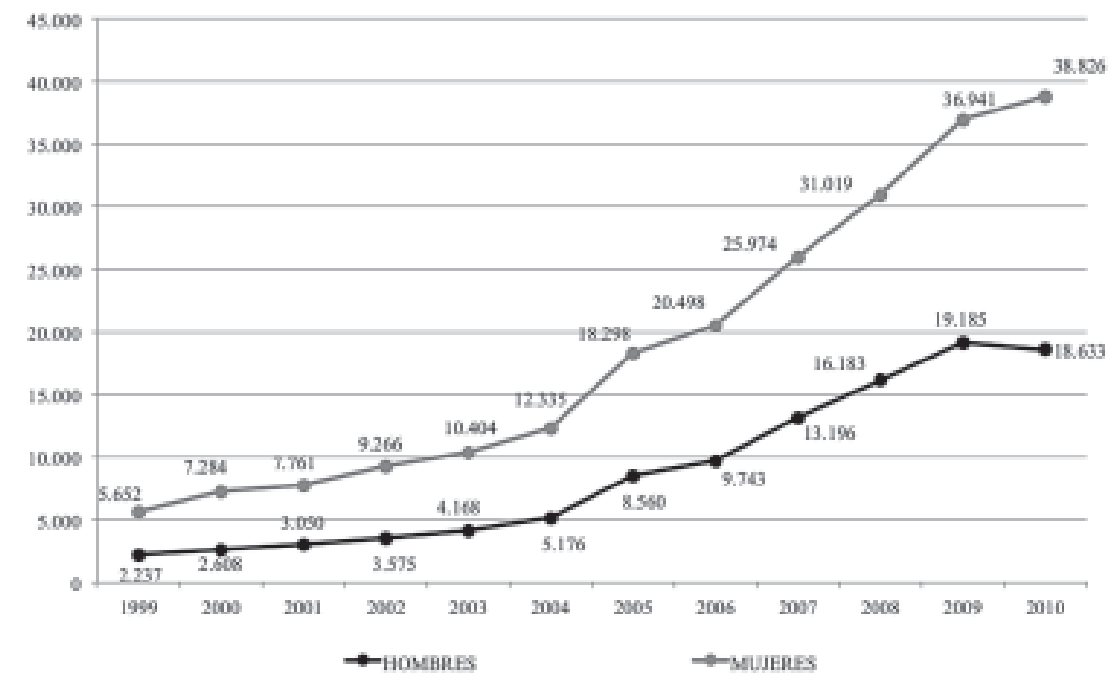

15 CARVAlHo y SOUZA, 2008; TÉCHIO, 2006.

${ }^{16}$ CARVALHO, 2007; Christiane CATARINO y Laura OSO 2000 Antonio IZQUIERDO-ESCRIBANO et al , 2003; PISCITELLI, 2008a. 17 MTIN (Ministerio de Trabajo e Inmigración), 1996-2010.
Los datos nos permiten observar que las mujeres corresponden a la mayoría entre los migrantes brasileños en España, ${ }^{15}$ como también es el caso para casi todos los colectivos migratorios latinoamericanos en este país. ${ }^{16}$ La feminización del colectivo brasileño es una tendencia que se viene confirmando desde la publicación de los primeros datos sobre migración por el Gobierno de España, ${ }^{17}$ pero que se viene intensificando notablemente en la última década. Observamos, sin embargo, un descenso tanto del número de mujeres como del de hombres empadronados entre 2009 y 2010 , lo que remite directamente a la crisis económica enfrentada por España desde 2008 que viene provocando migraciones de retorno entre la comunidad brasileña, en especial entre aquellos que no se encuentran en situación documental irregular en territorio europeo. Simultáneamente, el surgimiento de Brasil como una nueva potencia económica en el discurso de importantes medios de comunicación internacionales y las noticias de mejora económica en origen están impulsando este retorno. Una de las brasileñas que entrevistamos en Madrid, y que trabaja con la venta de seguros a inmigrantes brasileños nos comentaba que

Hay mucha gente que está indocumentada, pero que sigue aquí, pero hay un $40 \%$ de las mujeres que estaban indocumentadas, que volvieron a Brasil. La mayor parte de la gente, y lo sé por los listados del seguro de repatriación....Nosotros, para los seguros que

172 Estudos Feministas, Florianópolis, 21(1): 167-190, janeiro-abril/2013 
${ }^{18}$ PADILLA, 2007, encontraba esta misma circunstancia para el caso de las migrantes brasileñas en Portugal.

19 PISCITELLI, 2008a, 2008b; Paula Christofoletti TOGNI, 2008. fueron hechos el año pasado, nosotros tenemos una cartera, un listado y esto normalmente se renueva, y esto no pasó, porque esta gente ya no está aquí. Se cambiaron. Se cambiaron de España por la crisis. Hay gente que fue a Portugal, hay gente que fue a Londres, hay gente que fue a Italia, por la crisis. Yo también siempre estoy hablando con mis amigos de una empresa de envíos [agencia de envío de dinero regentada por Brasileños en Madrid], y esta gente también lo nota. Donde más se nota que se han ido los inmigrantes es en el envío de dinero, y el envío de dinero cayó a la mitad porque no hay gente...Y no hay trabajo. Y claro, en Brasil, yo he estado allí en el final del año [de 2009] y mira, yo tengo una familia muy grande allí, en el interior de São Paulo, entre Taubaté y Aparecida do Norte, y yo no vi nadie sin trabajo. Entonces yo creo que allí, ahora, empezó a crecer más que aquí. La cosa está mejorando allí. La gente que trabajó aquí un año, dos años y vio como estaba la situación, volvió para allá. (E. Madrid. 14 de julio de 2010).

Por otro lado, pese a que las brasileñas indocumentadas hayan empezado un camino de vuelta hacia Brasil, los datos permiten verificar que el número de mujeres que obtuvieran Tarjeta de Residencia en estos últimos dos años ha aumentado, pasando de 36.941 personas en enero de 2009 , para 38.826 personas en enero de 2010 , lo que denota una diferencia en el acceso a la regularización documental entre brasileñas y brasileños en este momento de crisis. En este sentido, los hombres empadronados en 2010 corresponden al $39 \%$ del total de brasileños, mientras los hombres con Tarjeta de Residencia corresponden solamente a un $32,4 \%$ del total. Esto significa que las mujeres son mayoría entre los brasileños, pero también que consiguen legalizarse con más facilidad que los hombres. ${ }^{18}$ Esto se debe, en gran medida, al expresivo número de mujeres brasileñas casadas con europeos, dato que comprobamos en nuestro trabajo de campo en Madrid, y que también es corroborado en otros trabajos sobre migración brasileña en Portugal e Italia. ${ }^{19}$ En gran medida, hay una importante frontera entre brasileñas y brasileños en condición migratoria en España y que está vinculada a la construcción de unas definiciones de género asociadas a la corporalidad femenina, a la manera como se entienden estas mujeres y sus capacidades sexuales en la sociedad española. Este conjunto de imaginarios, como veremos más adelante, favorecen un tipo específico de inserción de las brasileñas que a la vez que les somete a relaciones desiguales de género, les permite construir vínculos más estables de permanencia, como lo es el matrimonio. 
${ }^{20}$ En la medida en que las mujeres latinoamericanas fueron llegando a España, a partir de 1994, un interesante ciclo se instaura, fijando un proceso de retroalimentación: la migración alimenta el mercado de servicios domésticos a la vez que genera una demanda por estos servicios (CATARINO y OSO, 2000).

${ }^{21}$ CARVALHO, 2007, p. 6.

${ }^{22}$ CATARINO y OSO, 2000; Adriana GONZÁLEZ GIL y Marcela TAPIA LADINO, 2009; PISCITELLI, 2008a.

\footnotetext{
${ }^{23}$ Sonia PARELLA, 2000; 2003.
}

${ }^{24}$ CATARINO y OSO, 2000, p. 186.

25 PARELLA, 2000; 2003; 2005.

${ }^{26}$ PISCITELLI, 2008a.
Desde un punto de vista económico, sin embargo, el encasillamiento laboral sufrido por las mujeres brasileñas en España en general ( $y$ en Madrid, en nuestro caso específico) se vincula a la segmentación de un mercado laboral que condiciona a las mujeres latinoamericanas a los servicios domésticos y de cuidado de niños y ancianos: ${ }^{20}$

Esta feminización de la migración, sin dudas se relaciona con la modalidad y posibilidad de inserción de las migrantes en el mercado de trabajo, especialmente en el sector doméstico, que constituye un polo de atracción para la mujer independiente, jefe y sostenedora del hogar. Por otro lado, las mujeres latinoamericanas son representadas como dulces, calmas, pacientes, serviles y sumisas, un estereotipo que contribuye a valorarlas en el mercado del 'care', en el que son incluso preferidas, en ciertos locales de Europa, frente a trabajadoras de otras nacionalidades. ${ }^{21}$

Este mercado laboral traspasa a las mujeres latinas una parte importante del trabajo de reproducción de las familias autóctonas, en gran medida liberando las españolas de clase media de funciones que históricamente estuvieron a su cargo..$^{22}$ Este proceso permite a las mujeres autóctonas integrar el mercado profesional en condiciones antes impensables, y es doblemente el resultado y la causa de la transformación de las relaciones de género vividas por la sociedad española en los últimos treinta años. Se puede inferir que la asociación o el encasillamiento de las mujeres latinoamericanas en este segmento laboral es un proceso que traspasa una desigualdad de género estructural en la sociedad española a estas mujeres extranjeras, desplazando hacia ellas un conjunto de limitaciones, violencias y fronteras que ya no se viven tan extendidamente entre las españolas: ${ }^{23}$

Todo ello gracias a la transferencia de servicios, tradicionalmente realizados en el hogar, a una masa de la población que queda condenada al 'estatus de servidor' (Gorz, 1988). Esta segmentación del mercado laboral no sólo crea un ejército de reserva entre la población autóctona, sino que, a su vez, está determinada por la división internacional del trabajo. ${ }^{24}$

Además, la "personificación" de estas relaciones por las mujeres latinas tiende a yuxtaponer la desigualdad de género a un sentido de exclusión nacional y, crecientemente, a una diferenciación étnica/racial, ${ }^{25}$ lo que es especialmente notable en el caso de las brasileñas afro-descendientes, ${ }^{26}$ tema que abordaremos más adelante.

La desigualdad de las relaciones de género que encasillan las brasileñas en el mercado de los servicios

174 Estudos Feministas, Florianópolis, 21(1): 167-190, janeiro-abril/2013 
27 Emplearse "en negro" significa trabajar sin un contrato formal, sin ninguno aval o protección legal, en un régimen de horas excesivo $y$, por vía de regla, cobrando sueldos inferiores a los que se debiera - un conjunto de condiciones que favorece económicamente al empleador reproduciendo a la vez la exclusión social de estas mujeres. ${ }^{28}$ TÉCHIO, 2006.

domésticos y de cuidado de niños y ancianos también se manifiesta en una dimensión jurídica: la irregularidad documental suele ser bastante elevada en los acuerdos entre contratantes y prestadores de estos servicios, y esta circunstancia se convierte en un elemento de presión del que dispone el empleador. Esta es una realidad vivida cotidianamente por muchas de las mujeres brasileñas en Madrid, quienes son empleadas "en negro", como se suele decir. ${ }^{27}$ La ausencia de un contrato de trabajo impide que estas mujeres accedan a la Tarjeta de Residencia, lo que genera una importante concentración de las brasileñas en situación documental irregular en este sector. ${ }^{28}$ Como nos relataron algunas de nuestras entrevistadas que trabajan en estas condiciones, hay un temor constante por la amenaza de denuncias por parte de los empleadores autóctonos, lo que muchas veces mantiene estas mujeres en vínculos laborales perversos:

Es muy pesado todo. Estoy lejos de mi hija, no tengo dinero para salir de paseo, no tengo vida propia [...]. Vivo para trabajar. Además está la cosa de que en el trabajo no siempre te tratan muy bien. Yo tengo suerte, porque ahora estoy en casas donde la gente me trata bien, pero me pasó muchas veces de ser acusada de robar cosas, te miran de arriba hacia abajo... Brasileña, latina, ¿sabes? Siempre quieren hacerte trabajar más de lo que pagan y quieren pagar menos. Yo hice trabajos en que la persona [contratante] al final no te paga y tú no puedes hacer nada...Yo estoy ilegal, ¿cómo voy a decir a la policía que el fulano no me pagó? (l. Conversa personal en agosto de 2010. Notas del diario de Campo).

Profundizando el cuadro general sobre la situación laboral de los migrantes brasileños, encontramos que el $94,2 \%$ de los que poseen Tarjeta de Residencia en España (52.031 personas) tienen entre 16 y 64, encontrándose por lo tanto en edad económicamente activa. Un 4,94\% (3.708 personas) tiene menos de 15 , mientras tan solamente un 0,85\% (412 individuos) tienen más de 65 años. Observando estas cifras a partir de la variable sexo, notamos que la gran diferencia numérica entre hombres y mujeres se concentra justamente entre los y las migrantes en edad laboral. 


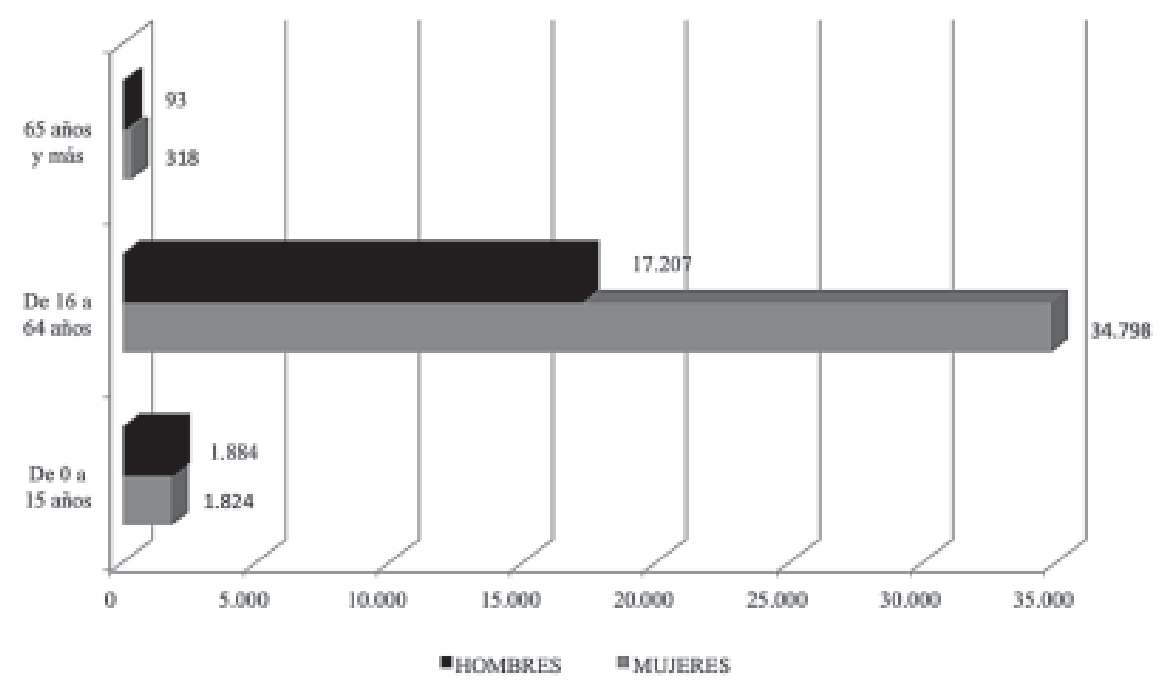

29 Aún así, es llamativo que solamente 23.678 de los 52.005 brasileños(as) en edad económicamente activa estén inscritos en la seguridad social, lo que a su vez puede indicar que estos migrantes estén marginados en relación a las garantías del Estado de Bienestar español.

Como el gráfico explicita, las mujeres brasileñas entre 16 y 64 años con Tarjeta alcanzan las 34.798 personas, lo que equivale al $67,3 \%$ de todo el colectivo de brasileños legalmente documentados. Esta información confirma lo que decíamos anteriormente sobre la predominancia de las mujeres como motor de la migración brasileña y nos permite inferir que los impactos económicos de esta migración tanto en lo que se refiere a las remesas a las localidades de origen, como en el capital utilizado para financiar la reagrupación familiar-descansan, casi siempre, en el trabajo de las brasileñas. Ellas constituyen las "cabezas" de las redes migratorias.

Estas afirmaciones también se verifican en los datos referentes a la afiliación de migrantes brasileños a la Seguridad Social de España, según los cuales las mujeres equivalen al $62,24 \%$ (14.738 personas) del total de brasileños asegurados, mientras los hombres figuran con un $37,76 \%$ (8.940 individuos). Observando la información de la afiliación a la Seguridad Social según intervalos de edad de cinco años, notamos que las mujeres son mayoría para todas las secuencias: ${ }^{29}$

176 Estudos Feministas, Florianópolis, 21 (1): 167-190, janeiro-abril/2013 


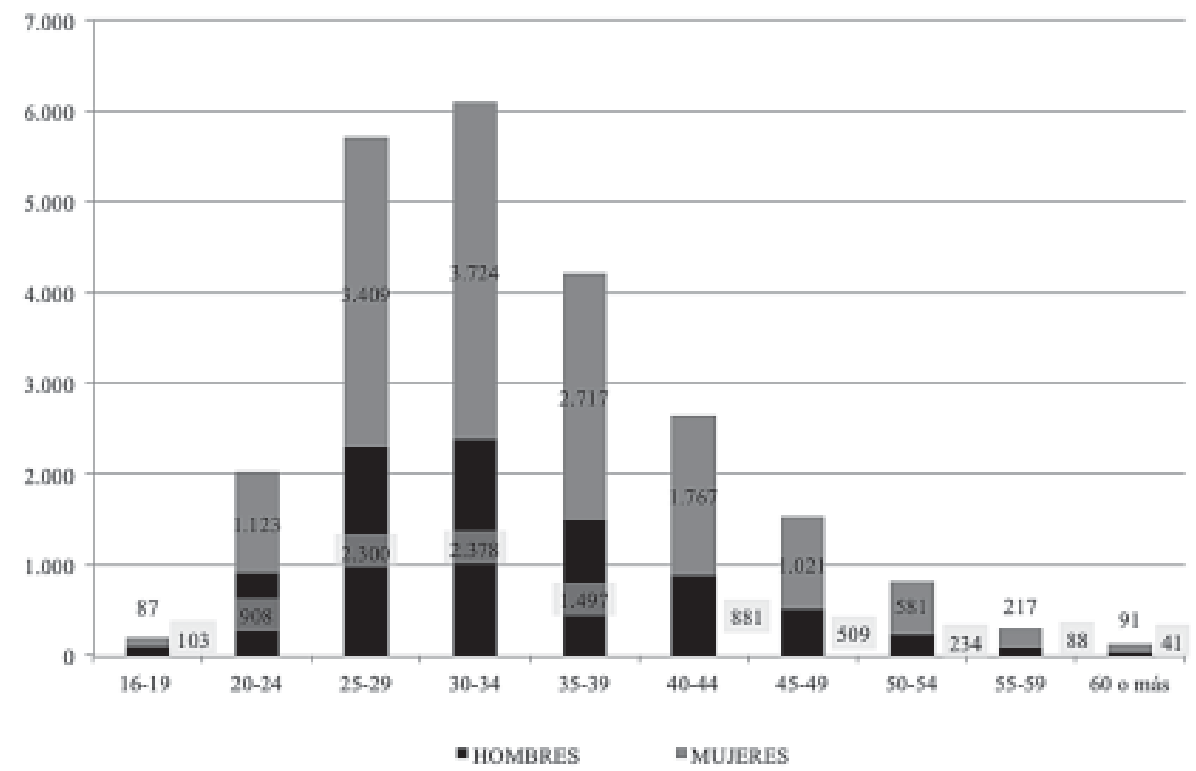

El $86,9 \%$ de los 23.678 de brasileños(as) vinculados a la Seguridad Social trabajan por "cuenta ajena", estando empleados en empresas, negocios y/o establecimientos administrados por terceros. El 13,1\% restantes están inscritos por "cuenta propia", una categoría que engloba a los profesionales liberales que trabajan como autónomos (abogados, arquitectos, odontólogos) y también a los pequeños emprendedores que regentan su propio negocio. En esta última categoría, las mujeres son más numerosas, una característica que tiene mucho impacto en la manera como la comunidad de brasileños se articula en Madrid. Esto ocurre porque los pequeños negocios regentados por brasileñas - en general panaderías, peluquerías, bares y restaurantes - constituyen los espacios de ocio donde uno puede encontrar una referencia simbólica, emocional, lingüística y personal a Brasil:

La mayor parte de la gente que montó sus negocios son brasileñas. Son mujeres brasileñas, más que hombres brasileños. [...] Está la pastelería de Doña Nena, [a la] que va mucha gente los sábados y domingos. Es como si tú estuvieses allí [en Brasil]. [...] Y 


\begin{abstract}
los sábados y domingos, a veces yo voy a la pastelería y parece que estoy en la casa de mi madre, porque tú ves la música sertaneja en la tele, que es la música del pueblo, y ves la gente hablando así, un poco caipira, hablando un poco pueblo... Como se escucharas así un salmantino y un sevillano aquí de España. Y ves aquella gente decir: 'me dá um pastel', 'eu quero uma cochina', y tienen zumos, y açaí. Parece que estoy allí [en Brasil]. Yo llamaba a mi madre [en Brasil] y le decía: 'mamá escucha' y ella me preguntaba 'idónde estás?', 'estoy en una pastelería brasileña'. [...] Y justo delante a la Doña Nena, está una peluquería...Es muy buena gente, la dueña. Tú llegas y ella te habla como si estuvieras en Brasil: '¿ya tomaste café? iNo! Vamos hacerte un café ahora mismo'. Y si tu llegas con calor, te dice: 'espera que voy a buscar una cerveza para ti'. (E. 14 de julio de 2010).
\end{abstract}

Estos pequeños emprendimientos regentados por las mujeres brasileñas son espacios que permiten una experiencia transnacional a los inmigrantes, ofreciéndoles vínculos con los que re-significar el desplazamiento migratorio, la identidad brasileña diaspórica, intercambiar favores, y recordar los sitios de origen - sea a partir de la comida, de las músicas, de la televisión brasileñas emitida en directo, o a través de la propia estética que se recrea en estos locales. En Madrid, las mujeres que regentan estos negocios se han convertido en puntos nodales a partir de los cuales las redes sociales de la migración brasileña se van tejiendo, lo que hace de ellas una referencia para toda la comunidad. Este conjunto de observaciones que hemos realizado empíricamente tienen su realidad confirmada en la expresiva estadística que ubica las mujeres brasileñas afiliadas a la seguridad social por "cuenta propia". 


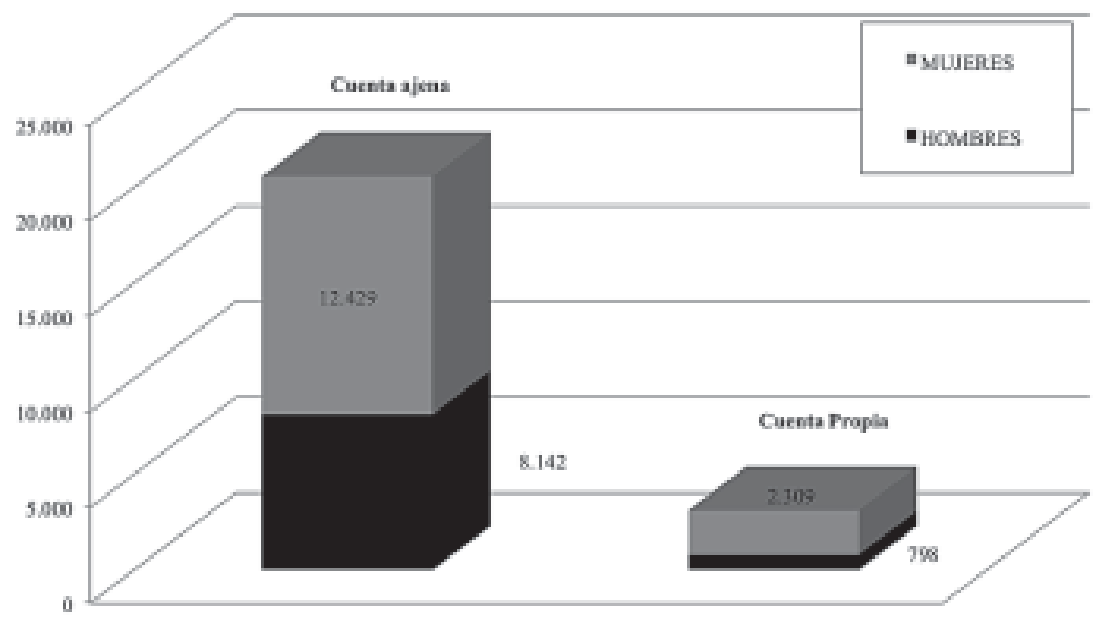

Quisiéramos destacar dos consecuencias importantes del liderazgo femenino en estos emprendimientos. El primero de ellos tiene que ver con el hecho de que el papel asumido por las mujeres brasileñas que regentan establecimientos comerciales como puntos de articulación social-espacial del colectivo brasileño en Madrid también les ha expuesto de manera particular a algunos de los conflictos a los que el colectivo enfrenta en la sociedad de recepción. Un ejemplo de este proceso son los conflictos vecinales junto a la población autóctona motivados por el tipo de usos del espacio público realizado por los y las brasileñas en estos establecimientos comerciales. En este sentido, se han vuelto comunes las denuncias realizadas por estos vecinos sobre el volumen de la música, el comportamiento "inapropiado" de los clientes de estos establecimientos en la calle, la ocupación de aceras con mesas y sillas, y el consumo "no moderado" de alcohol. Para la población autóctona, sin embargo, las brasileñas que regentan estos establecimientos son responsables por estas circunstancias, siendo directamente asociadas a los estereotipos que resultan de la vinculación de estas situaciones a la nacionalidad, o al carácter nacional brasileño. Así, acaba recayendo sobre ellas no solamente la responsabilidad de responder jurídicamente a las denuncias, como también la responsabilidad frente a las redes sociales de los brasileños en Madrid de defender el derecho de los migrantes por hacer uso del espacio público. 
${ }^{30}$ Alejandro GARCÉS, 2010.

La segunda consecuencia acerca de esta presencia femenina de liderazgo en los pequeños negocios tiene que ver con un cambio en el perfil económico estas migrantes. Un ejemplo claro de este proceso encontramos en las peluquerías "brasileñas". Hasta 2006 las brasileñas regentaban locales de estética solamente en barrios considerados "enclaves migratorios" de Madrid - en especial Usera, Aluche y Oporto, donde se concentra gran parte del colectivo brasileño - atendiendo básicamente a un público migrante latinoamericano. A partir de 2006, sin embargo, se asientan peluquerías promocionadas por su especial técnica de depilación en barrios con alto niveles de renta de Madrid, como lo es el de Salamanca:

Hace unos cuatro años, estaban todas solo por Usera, por Aluche, que era donde estaban los brasileños. Ahora hay muchas que están por Salamanca, por la calle Castellón, o por la [calle] Jorge Juan, o ahí donde está el metro Núñez de Balboa, ¿sabes?... iY son de gente brasileña! (E., 14 de julio de 2011).

Aquí, nos encontramos con que la misma práctica, realizada en los barrios de concentración migratoria y en barrios donde se concentra una población de alta renta, recibe dos tipos diferentes de valoración social. La primera, es estigmatizada como parte de aquello que les confiere a los inmigrantes su diferencia étnica-nacional frente a la población autóctona, mientras la otra se construye como un servicio de lujo, un consumo exótico que refuerza la distinción social de las élites autóctonas como "consumidoras de una moda global". ${ }^{30}$

Pero no solamente las mujeres documentadas encuentran en el auto-empleo una alternativa para alcanzar alguna autonomía laboral. Esta alternativa también es seguida por las mujeres indocumentadas que trabajando en los servicios domésticos, también optan por llevar a cabo pequeños emprendimientos informales, normalmente vinculados a los servicios de estética:

Hay muchas peluquerías brasileñas en Madrid y muchas chicas que hacen cuestión a domicilio atienden en casa 0 muchas veces atienden a las primas. Sí, porque no tienen papeles, porque tienen en su casa, yo qué sé, una habitación que ponen para trabajar con extensiones [de pelo], con manicure. con todo eso. Eso porque están ilegales...Como se dice, [ellas] están indocumentadas. [...] Hay mucho más mercado informal que formal entre las mujeres brasileñas. (E., 14 de julio de 2011).

Estas mujeres que gestionan sus negocios desde una condición de ilegalidad documental están, en gran 
${ }^{31}$ Anthony LEEDS y Elizabeth LEEDS, 1978.

${ }^{32}$ Janice E. PERLMAN, 2002, 2008

${ }^{33}$ Donna M. GOLDSTEIN, 2009.

\footnotetext{
36 PADILLA, 2008.
}

medida, adaptando a la realidad española un modelo de inserción económica femenina que viene desde hace por los menos cuatro décadas operando con las mujeres de baja calificación educacional formal en los grandes centros urbanos de Brasil. ${ }^{31}$ La presencia de estas mujeres como motor de la economía informal asociada a los tratamientos de belleza (peluquería, depilación, manicure, pedicura), en urbes como Río de Janeiro, mueve una economía sumergida fundamental para la reproducción de las familias de baja renta, constituyendo junto a los servicios domésticos un nicho económico que permite que ellas tengan más estabilidad en los momentos de crisis que los hombres no-escolarizados, normalmente empleados en sectores primarios que sufren gravemente con las oscilaciones económicas. ${ }^{32}$ Así, lo que notamos en Madrid es la transnacionalización de una estructura económica de larga duración en la sociedad brasileña y que encarga a las mujeres de baja renta la tarea de reproducción social de la familia. ${ }^{33}$ Pero lo que es sustancial aquí es no solamente el que este fenómeno implique un alto grado de explotación del trabajo femenino y una sobrecarga social sobre las mujeres en la sociedad brasileña. Lo que nos resulta interesante es que esta experiencia arma las mujeres de un tipo de capital social que les facilita el tránsito entre varias actividades económicas informales.

En otras palabras, las mujeres brasileñas pueden ser el motor de la migración porque han sido socialmente adaptadas a "navegar" entre funciones económicas informales muy específicas, constituyéndose como una mano de obra maleable no-calificada perfectamente adecuada a las necesidades que la sociedad española presenta desde fines del siglo XX. Sobre este último aspecto, concordamos con el análisis de Padilla ${ }^{34}$ para quien esta "informalización" del mercado laboral de las migrantes brasileñas se relaciona directamente con lo que la literatura de los emprendimientos étnicos ha solido denominar "estructuras de oportunidades", 35 es decir las condiciones micro o macro estructurales que las sociedades de destino ofrecen a la población migrante. En este sentido, el que las brasileñas puedan contar con un capital social que les prepara para la sobrevivencia en un mercado laboral informal no es la única razón por la que de hecho llegan a ocupar estos nichos económicos. Habría que considerar también el que el mercado informal sea aceptado como un definidor del tipo y dinámica de los pequeños emprendimientos en los países del Sur de Europa, especialmente Portugal y España, donde la informalidad ha tenido históricamente, un importante peso económico. ${ }^{36}$ 
${ }^{37}$ TÉCHIO, 2006.

${ }^{38}$ TÉCHIO, 2006.

${ }^{39} \mathrm{MACHADO} 2005 \mathrm{~b}$.

${ }^{40}$ Para un debate detallado sobre las redes de trata de mujeres brasileñas léase João PEIXOTO, 2007.

${ }^{41}$ OEA (Organización de los Estado Americanos), 2002.

${ }^{42}$ PISCITELLI, 2007, 2008a; 2008b.

${ }^{43}$ PISCITELLI, 2007, 2008a; 2008b. ${ }^{44}$ Gustavo LINS RIBEIRO, 1998 Takeyuki TSUDA, 2003; ZUBARAN 2008. Bernadete Beserra llegó a esta misma conclusión en su estudio sobre migrantes brasileñas en Los Ángeles: "Todas las brasileñas con quienes conversé sobre el tema eran conscientes del estereotipo. Algunas creían que el estereotipo restringía sus movimientos, promovía la idea de prostitución y, consecuentemente, producía un impacto negativo sobre las brasileñas, particularmente las que viven fuera" (BESERRA, 2007, p. 316).

${ }^{45}$ MACHADO, 2004a, 2004b $2005 a$.

\section{El peso del imaginario. El encasillamiento sexual-racial de mujeres brasileñas en Madrid}

Estudios recientes han demostrado que Portugal es una puerta de entrada de los brasileños en el continente Europeo y que muchas veces estos migrantes tienen como objetivo final un país más al norte. ${ }^{37}$ Lo que también se sabe, es que la migración brasileña mantiene un activo flujo entre Portugal y España, y que los inmigrantes muy a menudo alternan temporadas laborales en uno y otro país como una estrategia para mantenerse económicamente y para sortear las dificultades resultantes de la irregularidad documental. ${ }^{38}$ Hay un importante número de familias brasileñas "transnacionalizadas" entre ciudades españolas y portuguesas y también se nota un interesante flujo fronterizo de brasileños venidos de Portugal en las regiones españolas de Extremadura y Galicia.

Desafortunadamente, las redes de trata de mujeres brasileñas también suelen llegar a España desde Portugal, ${ }^{39}$ entrando en el país prioritariamente a partir de estas dos comunidades autónomas (Extremadura y Galicia) y distribuyéndose hacía otras regiones, especialmente las Islas Baleares y las ciudades costeras de Cataluña. ${ }^{40}$ De las 100 redes internacionales de trata de mujeres brasileñas identificadas por la Policía Federal de Brasil, 33 tiene España como destino final. ${ }^{41}$ El dato nos permite observar cómo la prostitución de mujeres brasileñas se ha convertido en una actividad masiva en territorio español, lo que doblemente se manifiesta en un perverso imaginario colectivo que asocia la mujer brasileña a la actividad. ${ }^{42}$

En gran medida, el nicho laboral de las brasileñas en la prostitución está mediado por un estereotipo de hipersexualidad fuertemente asociado al imaginario de "tropicalismo" con el que los y las brasileñas definen su identidad nacional en condición migratoria, ${ }^{43}$ y que viene acompañando la migración brasileña en diferentes partes del globo. ${ }^{44}$ Esta construcción, sin embargo, no se refiere únicamente a la manera como los migrantes entienden y elaboran su identidad. Ella se respalda en condiciones estructurales vinculadas a los imaginarios europeos y norteamericanos acerca de Brasil y de las brasileñas, reafirmando estereotipos que relacionan su identidad nacional al dominio de los bailes, músicas, y performances varias asociadas a este "tropicalismo" y ayudando a constituir un nicho económico al que Machado denominó el mercado de la alegría..$^{45}$ La forma como los europeos y estadounidenses identifican, clasifican y se relacionan con los y las brasileñas está en gran medida impactada por la permanencia de este 
46 MACHADO, 2004c, 2005a 2007

47 BESERRA, 2007; PISCITELLI, 2008a; 2008b.

${ }_{48}$ MACHADO, 2003.

49 PISCITELLI, 2007.

${ }^{50}$ TÉCHIO, 2006.

${ }^{51}$ BESERRA, 2007, p. 316.

${ }^{52} \mathrm{MACHADO}, 2004 \mathrm{C}$.

53 GUIZARDI, 2010; MACHADO 2003, 2004a.

${ }^{54} \mathrm{De}$ la misma manera, el que esta identidad exótica sea un medio de inserción en un mercado económico-laboral específico termina por producir una competencia entre los migrantes brasileños por definir quienes mejor representan o encarnan este estereotipo, activando una especie de lucha por asumir la "centralidad" del imaginario con que los autóctonos definen a la "brasileaneidad" (MACHADO 2004c, p. 260)

55 BESERRA, 2007.

${ }^{56}$ PISCITELLI, 2007.

${ }^{57}$ Empresa Brasileña de Turismo. Órgano estatal responsable por las políticas públicas relacionadas al turismo en Brasil.

58 Raymundo FAORO, 2001; Gilberto FREYRE, 1973.

59 Glycia EMRICH PINTO, 2005; Louise Prado ALFONSO, 2006. imaginario colonial ${ }^{46}$ acerca de la gente en los trópicos, ${ }^{47}$ que en el caso de las mujeres brasileñas es sintetizado por la noción de exotismo, ${ }^{48}$ erotismo, ${ }^{49}$ exuberancia/salvajismo sexual ${ }^{50}$ y de la supuesta legitimidad del ejercicio de poder del hombre blanco (colonizador) sobre estas mujeres, como manera de controlar y someter su salvajismo, manteniéndolas en un estado de docilidad:

En este sentido, la exotización ya no representa la preferencia por la diferencia, como la etimología de la palabra sugiere, pero una representación deformada que facilita y justifica la dominación. O sea, la relación entre exotizador y exotizado, tal como desarrollada en el mundo occidental, es delimitada por otra relación, aquella entre colonizador y colonizado. Es, por lo tanto, una relación de dominación, no de reciprocidad. ${ }^{51}$

Este proceso de exotización de los migrantes brasileños tiene un doble impacto sobre el colectivo. Por una parte, facilita su inserción económica en el nicho laboral en el que las sociedades receptoras encasillan a los y las brasileñas, lo que en gran medida facilita su permanencia y reproducción económica en dichas sociedades. ${ }^{52}$ Pero por otro lado, esta imagen genera un aprisionamiento de los migrantes dentro de este conjunto de estereotipos tropicales y sexuales, ${ }^{53}$ que en el caso de las mujeres específicamente, termina funcionando como un limitador para la asunción de mejores puestos laborales, manteniéndolas fuertemente asociadas al mercado del sexo. ${ }^{54}$

No obstante, es importante observar que esta imagen sexual de las mujeres brasileñas ha sido fuertemente promovida desde el propio estado brasileño, ${ }^{55}$ especialmente vinculada como elemento publicitario frente a la industria internacional del turismo, ${ }^{56} \mathrm{y}$ adoptada como sello institucional de la EMBRATUR ${ }^{57}$ Esta política de promoción de una sexualidad femenina "tropicalizada" fue intensificada entre 1970 y 2000 , marcando cómo el estado construye la apropiación del cuerpo de las mujeres como una potestad pública, reactualizando en gran medida una estructura institucional patriarcal que ha constituido los cimientos de la sociedad brasileña desde la colonización. ${ }^{58}$ Este mecanismo de explotación de la figura femenina ha recibido fuertes críticas en los últimos años, en partes gracias a la aún insuficiente promoción de políticas de igualdad de género en el país. En respuesta a estas críticas, se propuso una reforma en las concepciones propagandísticas de la EMBRATUR que llevó a la erradicación de las fotos de mujeres semidesnudas de la publicidad turística oficial brasileña. ${ }^{59}$

Los resultados de este cambio, sin embargo, están lejos de ser satisfactorios, puesto que los medios de 
60 BESERRA, 2007, también atribuye a la industría internacional del cine de Hoolywood una importante responsabilidad en la reprodución y difusión de una imagen sexualidazada de las mujeres brasileñas.

${ }^{61}$ Isabel Ferin CUNHA, 2008.

62 Tuvimos la oportunidad de constatar este hecho cuando una funcionaria de atención al público de un Centro Cultural de la ciudad de Madrid nos interpeló asombrada: "Pero, ¿tú eres brasileña y tiene estudios universitarios? Yo pensaba que todas las mujeres brasileñas venían aquí para otra cosa...Tu sabes, ino?...Las mujeres brasileñas que vienen aquí [a España] son todas prostitutas" (Madrid, 16 de noviembre de 2008).

63 PISCITELLI, 2007, p. 18.

\footnotetext{
${ }^{64}$ Simultáneamente, este estereotipo que asocia las mujeres brasileñas a unas características sexuales determinadas despierta cierta curiosidad entre los autóctonos facilitando un conjunto de relaciones y una convivencia que en muchos casos contribuye a su permanencia y regularización documental en España a partir del matrimonio (PISCITELLI, 2007). Otro autores, observaban este mismo fenómeno entre las migrantes brasileñas en Estados Unidos (BESERRA 2007) y en Portugal (MACHADO 2004a; TOGNI, 2008).
}

comunicación internacionales siguen vinculando la imagen de Brasil a la de las mujeres morenas, mulatas o negras bailando en trajes de baño en los carnavales de Río de Janeiro. ${ }^{60}$ Por otro lado, los medios de comunicación de los países de recepción en Europa siguen reproduciendo y reforzando el estereotipo que asocia las brasileñas a la prostitución, lo que ayuda a consolidar una imagen que nacionaliza, racializa y encasilla las migrantes de esta nacionalidad. 61

El estereotipo sexual que deviene de este imaginario pesa incisivamente sobre todas las mujeres brasileñas que entrevistamos en Madrid. ${ }^{62}$ Sobre este encuadre general de las brasileñas en España, Piscitelli afirmaba que

En el ámbito internacional, estas imágenes [de las mujeres brasileñas] tienden a ser erotizadas por medio de una construcción de nacionalidad atravesada por género que es racializada y sexualizada, pero no es necesariamente asociadas a los 'colores' de piel oscura (Pontes, 2004; Piscitelli, 2004). Y la operación de este juego de categorías aparece en la percepción sobre las brasileñas insertadas o no en la industria del sexo. ${ }^{63}$

Una de nuestras entrevistadas, quién se definía como "mujer blanca y de clase media", nos informaba que antes de venir a España tuvo que enfrentar la oposición de su madre:

Mi madre me decía: '¿Qué vas a hacer allá? Tú tienes diploma universitario, puedes trabajar aquí. Y tú sabes que todas las mujeres brasileñas que están afuera son prostitutas'. Me resultó muy difícil vencer esta resistencia...Mi madre aún insiste en que debo volver [a Brasil]. (J. Mayo de 2010).

En el relato de J., vemos cómo la vinculación de las brasileñas en condición migratoria a la prostitución también se constituye como un imaginario activo en el país de origen, alterando en gran medida la relación que incluso una joven con alto nivel de escolaridad, y proveniente de sectores sociales medios, construye sus relaciones familiares transnacionales. El ejemplo nos permite comprender que el peso del imaginario recae sobre todas las mujeres brasileñas, sea cual fuera su situación económica o el color de su piel. ${ }^{64}$ Sin embargo, esto no significa que este imaginario tenga el mismo peso para todas las migrantes. Encontramos, que el estereotipo de hipersexualidad se constituye de manera racializada, impactando más intensamente a las mujeres brasileñas afro-descendientes que a aquellas que la sociedad española considera "blancas". Este proceso de racialización consiste en 
${ }^{65}$ MACDONELL Y LOURENÇO, 2009, p. 239

${ }^{66}$ Así, "esa explicación, en la que la 'raza' es sexualizada, mantiene relaciones con la percepción de cómo, históricamente, fue creada y diseminada esa noción acerca de la femineidad brasileña. Pensadores sociales nacionales y también extranjeros consideran que una apreciación sexualizada de la brasileñidad es parte de los valores en términos de los cuales los brasileños se perciben. La idea es que esta construcción está basada en la literatura científica y de viajes de europeos que visitaron el país desde el siglo XVIII" (PISCITELLI, 2008a, p. 4).
Adjuntar un sentido racial a individuos, sub-grupos poblacionales y a fenómenos sociales, convirtiendo algo que pudiera ser sutil y fluido, por ejemplo la identidad racial, en una categoría relativamente fija. Este proceso (...) encasilla actores sociales, incluyéndose a los inmigrantes, independientemente del tiempo que llevan en destino, en jerarquías étnicoraciales que influencian su movilidad social, el acceso a recompensas y recursos societarios, y sobre todo, su calidad de vida. La racialización es aún más problemática cuando los actores sociales son caracterizados por otros en un sentido que es inconsistente con su propia auto-identidad racial. ${ }^{65}$

En este sentido, pesa sobre las brasileñas negras, morenas y mestizas una presión constante por establecer relaciones horizontales, por desvincularse de la diferencia jerárquica racial que se establece sobre ellas incidiendo como un estereotipo que vincula su supuesta raza a una condición física, entendida esta última como un estado permanente de "corrupción sexual":

Es como si yo tuviera siempre que probar que soy honesta...Y cansa. Cansa porque la gente ya te mira como si tú estuvieras dispuesta a tener relaciones sexuales con cualquiera, como si tú fueras solamente esto. Yo tuve muchos trabajos, como vendedora, como camarera, y siempre tuve que aguantar las bromas de los compañeros y las insinuaciones también. ( $\mathrm{S}$. Madrid. Abril de 2010).

La dinámica de identificación de las mujeres brasileñas a partir de este imaginario que les atribuye una hipersexualidad racializada tiene su correlato en un proceso de clasificación social. Este proceso, a su vez, consolida un mercado laboral para estas mujeres, normalmente vinculándolas a los servicios en bares, en casas nocturnas, a los servicios de estética y cuidado corporal, y a los servicios domésticos, pero fundamentalmente yuxtaponiendo en estas mujeres su supuesta sexualidad exuberante, su corporalidad y su color de piel a una condición nacional. ${ }^{66}$ En España, ser "brasileña" significa ser clasificada como corporalmente voluptuosa, dotada de habilidades corporales sexuales y, por vía se regla, tener la piel negra. Corporalidad, sexualidad y color se mezclan en un problemático encuadramiento nacional-racial que expone las brasileñas a difíciles situaciones laborales, a la vez que les garantiza algunos (pocos y precarios) mecanismos de inserción social.

\section{Referencias}

ALFONSO, Louise Prado. Embratur: formadora de imagens da nação brasileira. Campinas: UNICAMP, 2006. 
ALMEIDA, Alexandra Gomes de; REIS, Ellem Saraiva. "A imigração brasileira em Portugal: o perfil do imigrante e as conseqüências no mercado de trabalho luso". Actas del V Encontro Nacional sobre Migrações. Campinas: UNICAMP, 2007.

ARANGO, Joaquín. "La explicación teórica de las migraciones: luz y sombra". Revista Migración y Desarrollo, n. 1, p. 1-30, octubre 2003.

BESERRA, Bernadete. "Sob a sombra de Carmen Miranda e do carnaval: brasileiras em Los Angeles". Cadernos Pagu, n. 28, p. 313-344, enero-julio 2007.

CARVALHO, Flávio; SOUZA, Flávio. Qual migração BrasilEspanha? CSEM, 2008. Artigo publicado pelo Centro Scalabriniano de Estudos Migratórios. Disponível em: http:/ /www.csem.org.br/2008/qual_migracao_brasil_espanha flavio_carvalho.pdf.

CAR̄VALHO, Valéria Nely Cézar de. "Oscilações e tendências da migração latino-americana na Bélgica: uma análise do caso brasileiro". Actas del V Congreso Europeo de Latinoamericanistas. Bruselas: CEISAL, 2007.

CATARINO, Christiane; OSO, Laura. "La inmigración femenina en Madrid y Lisboa: hacia una etnización del servicio doméstico y de las empresas de limpieza". Papers, 60, p. 183-207, 2000.

CUNHA, Isabel Ferin. "Journalistic Coverage of Immigration in the Portuguese Television: 2003-2006". Observatorio (OBS) Journal, n. 7, p. 12-39, 2008.

EMRICH PINTO, Glycia. Esculturas em bronze: gênero e sexualidade nas propagandas turísticas voltadas para o público brasileiro. Campinas: UNICAMP, 2005.

FAORO, Raymundo. Os donos do poder. Formação do patronato político brasileiro. 3. ed. revista. Rio de Janeiro: Globo, 2001.

FREYRE, Gilberto. Casa Grande y Senzala. Formación de la familia brasileña bajo el régimen de la economía patriarcal. Venezuela: Biblioteca Ayacucho, 1973.

GARCÉS, Alejandro. Movimientos y localizaciones: espacios públicos y economías de la migración peruana en Santiago de Chile. 2010. Tesis Doctoral - Departamento de Antropología Social, Universidad Autónoma de Madrid.

"Comercio inmigrante y economías étnicas: síntesis y críticas de los debates vigentes". Polis - Revista de la Universidad Bolivariana, n. 29, 201 1. Disponível em: http:/ /polis.revues.org/1928.

GOLDSTEIN, Donna M. "Perils of Witnessing and Ambivalence of Writing: Whiteness, Sexuality, and Violence in Rio de Janeiro Shantytowns". In: HUGGINS, M. K., and GLEBBEEK, M. L. (eds.). Woman Fieldind Danger. Negotiating

186 Estudos Feministas, Florianópolis, 21 (1): 167-190, janeiro-abril/2013 
Ethnographic Identities in Field Research. New York: Rowman \& Littlefield Publishers, 2009. p. 227-250.

GOLZÁLEZ GIL, Adriana; TAPIA LADINO, Marcela. "Los contextos de origen y destino en la configuración del escenario transnacional Colombia-España". In: RIVAS RIVAS, Ana María; GOLZÁLVEZ TORRALBO, Hermínia. Familias transnacionales colombianas. Madrid: Catarata, 2009. p. 63-88.

GONÇALVES, Amanda Regina. "Entre o transnacionalismo e a relocalização: estratégias de integração de imigrantes brasileiros na Espanha". Actas del IX Coloquio Internacional de Geocrítica. Porto Alegre: UFRGS, 2007.

GORZ, André. Métamorphoses du travail-quête du sens. Critique de la raison économique. Paris: Galilée, 1988.

GUIZARDI, Menara Lube. "La favela presente: risas, llantos y la transnacionalización de la memoria de los líderes brasileños de la capoeira en Madrid". In: VIANELLO, Alvise; DÍAZ, Enrique (Eds.). Cultura y política ¿Hacia una democracia cultural? Barcelona: CIDOB, 2010. p. 79-94.

Todo lo que la boca come. Flujos, rupturas y fricciones de la capoeira en Madrid. 2011. Tesis Doctoral Departamento de Antropología Social, Universidad Autónoma de Madrid.

INE - Instituto Nacional de Estadísticas. Padrón Municipal. Explotación Estadística. Cifras Oficiales de Población desde 1996. INE, 2011 . Disponível em: http://www.ine.es/ jaxi $/$ menu.do?type $=$ pcaxis\&path $=\% 2 \mathrm{~F}+20 \% 2 \mathrm{Fe} 245 \% 2$ F\&file $=$ inebase\& $\mathrm{L}=0$.

IZQUIERDO ESCRIBANO, Antonio; LÓPEZ DE LERA, Diego; MARTÍNEZ BUJAN, Raquel. "The Favorites of the TwentyFirst Century: Latin American Immigration in Spain". Studi Emigrazione, n. 149, p. 98-124, 2003.

LEEDS, Anthony; LEEDS, Elizabeth. A sociologia do Brasil urbano. Rio de Janeiro: Zahar Editores, 1978.

LINS RIBEIRO, Gustavo. "O que faz do Brasil, Brazil. Jogos identitários em San Francisco". Brasília: Universidade de Brasília, 1998. (Serie Antropologia, 237).

MACDONELL, Judith; LOURENÇO, Cilene de. "You're Brazilian, Right? What Kind of Brazilian are You? The Racialization of Brazilian Immigrant Women". Ethnic and Racial Studies, v. 32 , n. 2, p. 239-256, 2009

MACHADO, Igor José de Renó. Cárcere público: processos de exotização entre imigrantes brasileiros no Porto, Portugal. Campinas: UNICAMP, 2003.

. "Afetividade e poder entre os imigrantes brasileiros no Porto". Cadernos Pagu, n. 23, p. 257-278, 2004a.

"Apontamentos para uma etnografia da imigração brasileira no Porto, Portugal". Actas del VIII Congresso Luso-Afro-Brasileiro de Ciências Sociais. Coimbra, 2004b. 
"Estado-nação, identidade-para-o-mercado e representações de nação". Revista de Antropologia (USP), v. 47, n. 1, p. 207-234, 2004c.

"Considerações sobre a construção de identidades brasileiras em Portugal". Actas de la Conferencia Internacional Migrações Transatlânticas e Transeuropéias. Lisboa, 2005a.

"Implicações da imigração estimulada por redes ilegais de aliciamento: o caso dos brasileiros em Portugal". SOCIUS Working Papers, n. 3, sin paginación, 2005b.

"Reflexões sobre a imigração brasileira em Portugal". Nuevo Mundo, Mundos Nuevos, 7 jun. 2007. Disponível em: http://nuevomundo.revues.org/index5889.html.

MASSEY, Douglas S., ARANGO, Joaquin et al. Worlds in Motion. Understanding International Migration in the End of the Millennium. Oxford: Clarendon Press, 1998.

MTIN - Ministerio de Trabajo e Inmigración de España. Anuario Estadístico de Extranjería. Secretaria de Estado de Inmigración y Emigración, España, 1996-2010. Disponível em: http://extranjeros.mtin.es/es/InformacionEstadistica/ Anuarios/.

OEA - Organización de los Estado Americanos. Pesquisa sobre tráfico de mulheres, crianças e adolescente para fim de exploração sexual comercial, PESTRAF - Brasil. Instituto Internacional de Leyes y Derechos Humanos, Comisión Interamericana de Mujeres e Instituto Interamericano del Niño, 2002. Disponível em: http:// www.childtrafficking.com/Docs/pestraf_2002_trafficking i.pdf

PADILLA, Beatriz. "Redes sociales de los brasileros recién llegados a Portugal: solidariedade étnica o empatía étnica?". SOCIUS Working Papers, n. 2, sin paginación, 2005.

"Estado del arte de las investigaciones sobre los brasileños y brasileñas en Portugal”. In: CASTILLO, Isabel Yépez del; HERRERA, Gioconda (Eds.). Nuevas migraciones latinoamericanas para Europa. Balances y desafíos. Quito: FLACSO, 2007. p. 69-94.

. "O empreendedorismo na perspectiva de gênero: uma primeira aproximação ao caso das brasileiras em Portugal". Migrações, n. 3, p. 191-215, 2008.

PARELLA, Sonia. "El trasvase de desigualdades de clase y etnia entre mujeres: los servicios de proximidad". Papers, n. 60 , p. $275-289,2000$.

. Mujer, migrante y trabajadora: la triple discriminación. Barcelona: Anthropos, 2003.

"Segregación laboral y vulnerabilidad social de las mujeres inmigrantes a partir de la interacción entre clase social, género y etnia". In: SOLÉ, Carlota; FLAQUER, Luis 
(Eds.). El uso de las políticas sociales por las mujeres inmigrantes. Madrid: Instituto de la Mujer, 2005. p. 97-138.

PEIXOTO, João. "Tráfico, contrabando e imigração irregular. Os novos contornos da imigração brasileira em Portugal". Sociologia, Problemas e Práticas, n. 53, p. 71-90, 2007.

PEREIRA, Mônica. Brasileiros recém-chegados na Bélgica. Percurso entre direitos e estratégias de (sobre)vivência. Bruxelas: Associação de Ajuda e Informação aos Migrantes em Situação Irregular ou Precária, 2008. Disponível em: http://abraco-asbl.be/documents/percurso_ entre_direitos_e_estrategias_de_(sobre)vivencia.pdf,

PERLMAN, Janice E. Marginality: From Myth to Reality in the Favelas of Rio de Janeiro 1969-2002. Boston: World Bank, 2002. Mega-Cities Project/Trinity College.

. "Caminos esquivos para salir de la pobreza. Movilidad intra e intergeneracional em las favelas de Río de Janeiro". In: NARAYAN, D.; PETESCH, P. (Eds.). Salir de la pobreza. Perspectivas interdisciplinares sobre la movilidad social. Boston: Banco Mundial, Mayol Ediciones, 2008. p. 225268.

PISCITELLI, Adriana. "Corporalidades em confronto. Brasileiras na indústria do sexo na Espanha". Revista Brasileira de Ciências Sociais, v. 22, n. 64, p. 17-32, 2007.

. ¿Actuando la 'brasileñidad'? Tránsitos entre circuitos de turismo sexual y los mercados del sexo y matrimonial europeo". Actas del Latin American Studies Association Annual Meeting. Rio de Janeiro, 2008a.

- "Sexo tropical em um país europeu: migração de brasileiras no marco do turismo sexual internacional". Revista Estudos Feministas, v. 15, n. 3, p. 717-744, 2008b.

PONTES, Luciana. "Mulheres brasileiras na mídia portuguesa". Cadernos Pagu, n. 23, p. 229-256, 2004.

TÉCHIO, Katia. "Imigrantes brasileiros não documentados: uma análise comparativa entre Lisboa e Madri". SOCIUS Working Papers, n. 1, sin paginación, 2006.

TOGNI, Paula Christofoletti. "Os fluxos matrimoniais transnacionais entre brasileiras e portugueses: gênero e migração". SOClUS Working Papers, n. 1, sin paginación, 2008.

TSUDA, Takeyuki. Strangers in the Ethnic Homeland: Japanese Brazilian Return Migration in Transnational Perspective. New York: Columbia University Press, 2003.

VILLA, Miguel; PIZARRO-MARTíNEZ, Jorge. "Tendencias y patrones de la migración internacional en América Latina y el Caribe". In: CEPAL. La migración internacional y el desarrollo en las Américas. Santiago de Chile: CEPAL, 2001. p. 21-38. (Serie Seminarios y Conferencias, 15).

ZUBARAN, Carlos. "The Quest for Recognition: Brazilian Immigrants in the United States". Transcultural Psychiatry, v. 45, n. 4, p. 590-610, 2008. 
[Recebido em janeiro de 2012 , reapresentado em abril de 2012 e aceito para publicação em maio de 2012]

\begin{abstract}
Stereotypes, Identities, Roles and Economic Niches of Brazilian Women Immigrants in Madrid

Abstract: The Brazilian women correspond to $65 \%$ of the Brazilian immigrants in Spain. This feminization of the displacement is deeply related with a change of the gender relations lived by these women both in Brazil and in host society. In Madrid, Brazilian women are protagonists of a new kind of entrepreneurship. They run small businesses in the field of restoration and of aesthetics and beauty. Nevertheless, they are most commonly employed in low-paid jobs, generally related with domestic services and child/elder care, and with prostitution - being in many cases associated with a stereotype of hyper-sexuality that influences the economic niches they can or can't access. The aim of this paper is to analyze the economic roles of Brazilian immigrants in Madrid, also discussing the imaginaries of the host society with which they dialog to make their economic insertion feasible in Spain.
\end{abstract}

Key Words: Immigration; Brazilian Women; Gender; Sexual Stereotypes; Economic Niches. 